\title{
Transforming Community Cancer Care: The Ottawa Regional Cancer Foundation's Cancer Coaching Practice
}

\author{
Linda Eagen, MBA, Founder of Cancer Coaching ${ }^{1}$; Johanne Levesque, BScN, RN, MPA ${ }^{1}$
}

${ }^{1}$ Ottawa Regional Cancer Foundation

\section{A BSTRACT}

Community services are an increasingly important part of the healthcare landscape. Services that work to empower patients and their caregivers are having a positive impact on health outcomes and helping to reduce per capita costs of healthcare. According to the 2015 Canadian Cancer Statistics Report, by 2030 the annual number of new cancer cases in Canada is expected to increase by $79 \%$ [1]. Community-based cancer services, in particular, are urgently required to meet the growing demand for care as the complexity of the disease and its treatment continues to grow.

\section{RÉ S U MÉ}

Les services communautaires jouent un rôle de plus en plus important dans les soins de santé. Les services qui veillent à habiliter les patients et leurs proches aidants ont un effet positif sur les résultats en matière de santé et aident à réduire les coûts par personne des soins de santé. D'ici 2030, le nombre annuel de nouveaux cas de cancer au Canada devrait augmenter de 79 \% selon le rapport Statistiques canadiennes sur le cancer 2015 [1]. Des services communautaires pour le traitement du cancer, notamment, sont requis de toute urgence afin de répondre à la demande croissante de soins, alors que la complexité de la maladie et de son traitement ne cesse de croître.

This commentary outlines how the Ottawa Regional Cancer Foundation's Cancer Coaching practice is meeting the needs of cancer patients, their families, and caregivers-and helping to reduce the costs and demands on the healthcare system.

\section{WHAT IS CANCER COACHING?}

Cancer Coaching is a person-centred, solution-focused health intervention developed by the Ottawa Regional Cancer Foundation. Cancer Coaching actively engages clients in their own care through individual and group coaching consultations with a regulated healthcare practitioner. The program uses the client's frame of reference (i.e. their experiences, definitions of health and well-being, values and preferences) as the starting point to identify health goals, and then provides navigation, education, support, practical guidance, and skills development to help the client achieve their short and long-term goals. The Cancer Coaches help clients regain a sense of autonomy, improve health outcomes, and enhance quality of life. Cancer Coaching is open to people at all stages of diagnosis and treatment and does not require a physician's referral.

Cancer Coaching, as practiced at the Ottawa Regional Cancer Foundation, is an extension of three different programs: HealthChange ${ }^{\circledR}$ Methodology, a patient-centred health service delivery methodology developed by HealthChange ${ }^{\circledR}$ Associates (Australia), the Canadian Partnership Against Cancer's guide to cancer navigation, and the International Coaching Federation's best practices and ethical standards. By working with these partner organizations, the Cancer Foundation developed a unique program that has been shown to be effective in improving health and quality of life outcomes across the health continuum. The health continuum is an integrated system of healthcare that follows a patient ensuring they have knowledge and access to the services that best meet their needs. A health continuum model offers more comprehensive patient-centred care.

The Cancer Coaching practice is modeled on the Macmillan Cancer Support program in the U.K. and the Livestrong Survivorship Centers of Excellence in the U.S. When the Cancer Foundation began developing the Cancer Coaching service in 2010, survivorship care was a relatively new concept in Canada. It began emerging following the World Health Organization's recognition of cancer as a chronic disease. In Canada, $63 \%$ of cancer patients are expected to live at least five years post-diagnosis [2]. There is currently no national network of community-based services to help people who are living with the short or long-term effects of cancer and its treatments. Cancer Coaching is designed to help all those impacted by cancer-from diagnosis, through to treatment and end-of-life care-deal with their personal changes and overcome obstacles.

The effects of cancer span all elements of a person's life-physical, emotional and practical-and can last for weeks, months, or even years after the completion of treatment. Countries such as the U.S., U.K. and Australia have demonstrated a series of posi- 
tive outcomes when health coaching is implemented, including patients having a better adherence to treatment, better coping skills, and the ability to better take care of themselves. According to the report, Motivational Interviewing in Health Care: Helping Patients Change Behavior, this type of patient-centered coaching outperforms simple advice-giving-based approaches in $80 \%$ of clinical studies [3] and has been shown to be effective for supporting better healthcare outcomes across the care continuum [4].

\section{WHAT IS THE ROLE OF THE CANCER COACH ON A PATIENT'S HEALTHCARE TEAM?}

Cancer has a lasting impact on a person's health, functioning, sense of security, well-being, and quality of life. Survivors of cancer and their families struggle with life-altering decisions and how to cope with the effects of cancer treatment.

The Cancer Foundation's Cancer Coaching practice is based on three key processes: the first focuses on building a patient-centred alliance, the second helps the patient form an intention to act, and the third helps the patient convert their intention into meaningful action.

\section{HOW DOES CANCER COACHING IMPROVE HEALTH OUTCOMES?}

Coaching activities embed patient-centered care, health literacy, self-management support, and sustained behaviour change. The six key areas of the Cancer Coaching practice include: (1) assessing the needs and resources of the patient, (2) exchanging information and providing education regarding any number of client identified needs, (3) accelerating access to services and resources, (4) helping with the interdisciplinary coordination and integration of care, (5) providing support with a focus on patient empowerment, and (6) building self-advocacy competencies that aid in identifying system barriers and solutions.

The main role of the Cancer Coach is to assist the client in bringing about change that the client holds as important for improved health and quality of life outcomes. Some clients struggle with difficult decisions about treatment options, and are faced with various opinions from their network of family, friends, and healthcare providers. Cancer Coaches do not offer medical advice or treat cancer, but they work with patients to help them wade through the options presented to them by their health team. They work together, so the patient can make informed and timely decisions and play an active role in their overall health. Cancer Coaches can also provide clients with current and reliable research information on cancer treatment and care options.

A recent client survey from the Cancer Foundation shows pa- tients who have received Cancer Coaching were better able to cope with life, better able to keep themselves as healthy as possible, have improved quality of life and feel they are part of a connected cancer care team [5]. According to doctors, patients who have experienced coaching have increased confidence in their capacity to make and sustain health changes and, because of that, they are more likely to adhere to evidence-based treatment and referral guidelines and recommendations.

\section{HOW DOES CANCER COACHING BENEFIT FAMILY PHYSICIANS?}

Patients who are diagnosed with cancer face a unique set of challenges associated with the disease and its treatments. It is estimated that 1 in 4 cancer patients have clinical depression [6], and $30 \%$ require more information about their treatment options [7], education about their diagnosis, and encouragement to seek additional help. The study also found that $35-40 \%$ of cancer patients require specialized or professional intervention for symptom management and distress.

With increased pressures on the healthcare system, medical professionals, on average, have 15 minutes per visit to spend with their patients. Physicians who participated in a pilot project of referring patients to the Cancer Foundation's Cancer Coaching practice confirmed that after receiving individual coaching, their patients were better prepared for their medical appointments and could maximize the time with their physicians and focus on key issues. In addition, they confirmed that the patient-provider interactions were more meaningful and effective, which resulted in a more efficient use of time.

Clients who access Cancer Coaching often struggle with the following areas: dealing with stress, caregiver support, learning about resources available in the community, managing posttreatment transitions, managing and improving fatigue and grief and bereavement support. Other challenges include managing the physical, informational, emotional, and practical demands of cancer and dealing with barriers such as lack of money, social supports, difficulties with health literacy, mental and medical comorbidities, and multicultural approaches to health.

\section{ARE THERE PLANS TO EXPAND THE CANCER COACHING PRACTICE?}

The long-term vision for the Cancer Foundation is to make Cancer Coaching available to everyone diagnosed with cancer, and to share the knowledge gained through the Cancer Coaching practice with other chronic disease areas. To reach that goal in Eastern Ontario means building the capacity to serve approximately 10,000 people at any given time. In the Champlain Local Health Integration Network (LHIN) there are an estimated 


\section{Commentary}

7,900 new cancer diagnosis every year [8]. The Champlain LHIN is one of fourteen community-based organizations established by the Ontario Ministry of Health and Long-Term Care to help with the integration of healthcare services at the regional level. To expand the reach of Cancer Coaching, the Cancer Foundation has partnered with a number of health care providers, including Winchester District Memorial Hospital, Hospice Care Ottawa, which is a community-based organization that provides palliative and end-of-life care, and the Vanier Community Service Centre, which is a community development organization that offers a variety of programs and services to its clientele.

The Cancer Foundation has also developed, in collaboration with York University and HealthChange ${ }^{\circledast}$ Associates (Australia), a program designed to train healthcare providers in the delivery of the Cancer Foundation's Cancer Coaching practice, in order to ensure consistency and quality of the client experience.

\section{CONCLUSION}

Cancer incidence rates are on the rise, but thanks to improved screening programs and advancement in cancer research, patients have access to earlier diagnosis and better treatment options. The result: more people are surviving the disease and experiencing an improved quality of life.

With these scientific discoveries, cancer is more widely viewed today as a chronic illness and one that can, for the majority of cases, be treated and managed. This has resulted in a significant paradigm shift in the healthcare system, moving patients away from acute care in hospital to a community-based setting.

The Ottawa Regional Cancer Foundation's Cancer Coaching practice is an innovative solution that serves as the connector for cancer care. With the use of technology and enhanced communications systems, patients can access information and make their own decisions about what is best for them. They are emerging as informed consumers of healthcare, and are taking an active approach to their own healthcare. The Cancer Coach works in collaboration with the patient, empowering them to make informed decisions about their own care and share in the decision-making process with their healthcare practitioner.

More information about the Ottawa Regional Cancer Foundation's Cancer Coaching practice can be found at www.ottawacancer.ca or by calling (613) 247-3527.

\section{REFERENCES}

1. Canadian Cancer Society, Statistics Canada, Public Health Agency of Canada, Provincial/Territorial Cancer Registries. Special topic: Predictions of the future burden of cancer in Canada. Canadian Cancer Statistics, Chapter 7 , page 95 [Internet]. May 2015. Available from: http://www.cancer.ca/ / media/cancer.ca/CW/cancer\%20information/cancer\%20101/Canadian\%20
cancer\%20statistics/Canadian-Cancer-Statistics-2015-EN.pdf?la=en\%20Canadian\%20Cancer\%20Statistics, $\% 202015$

2. Canadian Cancer Society, Statistics Canada, Public Health Agency of Canada, Provincial/Territorial Cancer Registries. Special topic: Predictions of the future burden of cancer in Canada. Canadian Cancer Statistics, Chapter 5, page 60 [Internet]. May 2015. Available from: http://www.cancer.ca/ / media/cancer.ca/CW/cancer\%20information/cancer\%20101/Canadian\%20 cancer\%20statistics/Canadian-Cancer-Statistics-2015-EN.pdf?la=en\%20Canadian\%20Cancer\%20Statistics,\%202015.

3. Rubak S, Sandboek A, Lauritzen T, Christensen B. Motivational Interviewing: a systematic review and meta-analysis. Br J Gen Pract. 2005;55(513):305-12.

4. Rollnick, S, Miller, WR, Butler CC. Motivational Interviewing in Health Care: Helping Patients Change Behavior. New York: The Guilford Press; 2008

5. Ottawa Regional Cancer Foundation. Cancer Coaching Client Feedback Survey, 2014-2015, percentages refer to survey respondents who agreed completely or somewhat to survey questions.

6. National Cancer Institute - Depression (PDQ $\left.{ }^{\circledR}\right)-H e a l t h$ Professional Version, [Internet]. March 2016. Available from: https://www.cancer.gov/aboutcancer/coping/feelings/depression-pdq.

7. Howell, D., Currie, S., Mayo, S. et al. A Pan-Canadian Clinical Practice Guideline: Assessment of Psychosocial Health Care Needs of the Adult Cancer Patient, Toronto: Canadian Partnership Against Cancer (Cancer Journey Action Group) and the Canadian Association of Psychosocial Oncology, May 2009.

8. Ministry of Finance (\% population $>50$ ). Quick Statistics: 2016 Projected Data. March 2016. Available from: http://www.csqi.on.ca/by_lhin/champlain_Ihin/. Notes: Projected new cases are based on the NCI SEER standards for counting multiple primary cancers, which were adopted by the Ontario Cancer Registry for cases diagnosed in 2010 and beyond. 